\title{
Prognostic Factors in Patients Irradiated for Recurrent Head-and-Neck Cancer
}

\author{
DANIEL SEIDL ${ }^{1}$, STEVEN E. SCHILD ${ }^{2}$, BARBARA WOLLENBERG ${ }^{3}$, SAMER G. HAKIM $^{4}$ and DIRK RADES ${ }^{1}$ \\ Departments of ${ }^{1}$ Radiation Oncology, ${ }^{3}$ Oto-Rhino-Laryngology and Head and Neck Surgery and \\ ${ }^{4}$ Oral and Maxillofacial Surgery, University of Lübeck, Lübeck, Germany; \\ ${ }^{2}$ Department of Radiation Oncology, Mayo Clinic, Scottsdale, AZ, U.S.A.
}

\begin{abstract}
Background/Aim: Many patients with recurrent head-and-neck cancer have poor outcomes. Predictive factors allowing judgment of the patient's prognosis are important for treatment individualization. This study aimed to identify such factors after irradiation of locoregional recurrence. Patients and Methods: In 60 patients irradiated for locoregionally recurrent head-and-neck cancer, 12 factors were evaluated regarding freedom from second locoregional recurrence and survival, namely gender, tumor site, initial tumor stage, primary treatment, time between cancer diagnosis and irradiation of locoregional recurrence, age, performance score, tumor and nodal category of recurrence, upfront surgery, radiation dose and concurrent chemotherapy. Results: On Cox regression analysis, performance score $(p=0.002)$ and nodal category $(p=0.004)$ significantly affected survival. Good performance score $(p=0.021)$ and low nodal category $(p=0.002)$ were also significantly associated with freedom from a second recurrence. Conclusion: Independent predictors of survival and freedom from second locoregional recurrence were identified as factors facilitating individualized treatment of patients with locoregionally recurrent head-and-neck cancer.
\end{abstract}

More than $50 \%$ of patients with head-and-neck cancer experience locoregional recurrence, which is frequently associated with a poor outcome (1-3). Many of these patients receive radiotherapy (RT) or radiochemotherapy (RCT), administered either as definitive treatment or following surgery for recurrence. In order to assign the best possible

This article is freely accessible online.

Correspondence to: Professor Dirk Rades, MD, Department of Radiation Oncology, University of Lübeck, Ratzeburger Allee 160, 23538 Lübeck, Germany. Tel: +49 45150045401, Fax: +49 45150045404, e-mail: rades.dir@gmx.net

Key Words: Head-and-neck cancer, recurrence, radiation therapy, prognoses, outcomes. treatment to a specific patient with a locoregional recurrence of head-an-neck cancer who has been identified as a suitable candidate for radiotherapy, it would be very important to be able to judge the patient's outcome in terms of freedom form a second locoregional recurrence and survival. Such a judgment would be considerably facilitated by knowing predictive factors for both endpoints. Therefore, this study was initiated to identify such factors in a cohort of patients irradiated for locoregionally recurrent head-and-neck cancer.

\section{Patients and Methods}

This retrospective study included 60 patients irradiated for locoregionally recurrent head-and-neck cancer. In this series, 12 factors were evaluated regarding freedom from a second locoregional recurrence and survival following irradiation of recurrent head-andneck cancer. The 12 factors were gender, tumor site (oropharynx versus hypopharynx, larynx and oral cavity), initial tumor stage according to American Joint Committee on Cancer (AJCC) classification (I-II versus III-IV), primary treatment (surgery alone versus $\mathrm{RT} / \mathrm{TCT}$ alone and surgery plus $\mathrm{RT} / \mathrm{RCT}$ ), time between cancer diagnosis and irradiation of locoregional recurrence $(\leq 24$ versus $>24$ months), age at RT of locoregional recurrence ( $\leq 64$ versus $\geq 65$ years), performance score according to Eastern Cooperative Oncology Group (ECOG) at RT of locoregional recurrence (0-1 versus 2), tumor category of recurrence ( $\mathrm{rT}$ ) [rT1-2 versus $\mathrm{rT} 3-4$ and Tx (=rT-category unknown)], nodal-category of recurrence (rN) (rN01 versus $\mathrm{rN} 2$ ), upfront surgery of recurrence (no versus yes), radiation dose for the recurrence ( $<60$ Gy versus $\geq 60 \mathrm{~Gy}$ ) and concurrent chemotherapy for the recurrence (no versus yes).

Initially, univariate analyses of the 12 factors were performed (Kaplan-Meier method and log-rank test) (4). The factors that gained significance $(p<0.05)$ were afterwards evaluated in a multivariate fashion with a Cox regression analysis.

\section{Results}

According to the results of this study, survival was significantly affected on univariate analysis by performance score at RT of locoregional recurrence $(p<0.001)$, $\mathrm{N}$-category of the recurrence $(p=0.041)$, surgery for the recurrence $(p=0.015)$ and by the radiation dose for the 
Table I. Overall survival following irradiation of recurrent head-and-neck cancer.

\begin{tabular}{|c|c|c|c|c|}
\hline & At 1 year $(\%)$ & At 2 years $(\%)$ & At 3 years $(\%)$ & $p$-Value \\
\hline \multicolumn{5}{|l|}{ Gender } \\
\hline Female $(n=18)$ & 66 & 53 & 53 & \\
\hline Male $(n=42)$ & 64 & 56 & 50 & 0.87 \\
\hline \multicolumn{5}{|l|}{ Tumor site } \\
\hline Oropharynx $(n=25)$ & 72 & 67 & 56 & \\
\hline Hypopharynx $(\mathrm{n}=1)$ & 0 & 0 & 0 & \\
\hline Larynx $(n=20)$ & 70 & 58 & 58 & \\
\hline Oral cavity $(n=14)$ & 50 & 34 & 34 & 0.09 \\
\hline \multicolumn{5}{|l|}{ Initial tumor stage } \\
\hline AJCC I-II $(n=47)$ & 70 & 61 & 55 & \\
\hline AJCC III-IV $(n=13)$ & 43 & 28 & 28 & 0.16 \\
\hline \multicolumn{5}{|l|}{ Primary treatment } \\
\hline Surgery alone $(n=48)$ & 69 & 57 & 54 & \\
\hline $\mathrm{RT} / \mathrm{RCT}$ alone $(\mathrm{n}=3)$ & 33 & 33 & 33 & \\
\hline Surgery plus RT/RCT $(\mathrm{n}=9)$ & 52 & 52 & n.a. & 0.41 \\
\hline \multicolumn{5}{|c|}{ Time between cancer diagnosis and irradiation of locoregional recurrence } \\
\hline$\leq 24$ Months $(\mathrm{n}=30)$ & 57 & 43 & 38 & \\
\hline$>24$ Months $(n=30)$ & 73 & 66 & 61 & 0.08 \\
\hline \multicolumn{5}{|c|}{ Age at RT of locoregional recurrence } \\
\hline$\leq 64$ Years $(n=32)$ & 75 & 65 & 56 & \\
\hline$\geq 65$ Years $(n=28)$ & 52 & 44 & 44 & 0.20 \\
\hline \multicolumn{5}{|l|}{ ECOG score at RT of recurrence } \\
\hline $0-1(n=34)$ & 88 & 75 & 68 & \\
\hline $2(n=26)$ & 33 & 26 & 26 & $<0.001$ \\
\hline \multicolumn{5}{|l|}{ T-Category of recurrence } \\
\hline rT1-2 (n=13) & 69 & 59 & 49 & \\
\hline rT3-4 $(n=30)$ & 69 & 61 & 61 & \\
\hline $\operatorname{rTx}(n=17)$ & 53 & 41 & 34 & 0.12 \\
\hline \multicolumn{5}{|l|}{$\mathrm{N}$-Category of recurrence } \\
\hline rN0-1 $(n=34)$ & 70 & 70 & 66 & \\
\hline $\mathrm{rN} 2(\mathrm{n}=26)$ & 58 & 36 & 32 & 0.041 \\
\hline \multicolumn{5}{|l|}{ Surgery for recurrence } \\
\hline No $(n=23)$ & 51 & 33 & 26 & \\
\hline Yes $(n=37)$ & 73 & 67 & 64 & 0.015 \\
\hline \multicolumn{5}{|l|}{ Radiation dose for recurrence } \\
\hline$<60$ Gy $(\mathrm{n}=14)$ & 31 & 31 & 31 & \\
\hline$\geq 60$ Gy $(n=46)$ & 74 & 62 & 57 & 0.021 \\
\hline \multicolumn{5}{|c|}{ Concurrent chemotherapy for recurrence } \\
\hline No $(n=20)$ & 65 & 60 & 60 & \\
\hline Yes $(n=40)$ & 64 & 52 & 46 & 0.60 \\
\hline
\end{tabular}

AJCC: American Joint Committee on Cancer, RT: radiotherapy, RCT: radiochemotherapy, ECOG: Eastern Cooperative Oncology Group, n/a: not available, significant $p$-values are shown in bold.

recurrence $(p=0.021)$ (Table I). On Cox regression, performance score $[$ risk ratio $(\mathrm{RR})=3.69 ; 95 \%$ confidence interval $(\mathrm{CI})=1.65-8.40 ; p=0.002]$ and $\mathrm{N}$-category $(\mathrm{RR}=3.20$; $95 \% \mathrm{CI}=1.45-7.18 ; p=0.004)$ maintained their significant association with survival. For the radiation dose, a trend was found $(\mathrm{RR}=2.39 ; 95 \% \mathrm{CI}=0.88-6.21 ; p=0.09)$. Surgery was no longer significant (RR 1.37; 95\% $\mathrm{CI}=0.58-3.21 ; p=0.47$ ).

Considering locoregional control, a significant impact on univariate analysis was seen for laryngeal cancer $(p=0.020)$, initial tumor stage $(p=0.017)$, performance score at RT of locoregional recurrence $(p=0.004)$, N-category of the recurrence $(p=0.025)$, surgery for the recurrence $(p=0.004)$ and radiation dose for the recurrence $(p=0.032)$ (Table II). In the subsequent Cox regression, again performance score $(\mathrm{RR}=3.09 ; 95 \% \mathrm{CI}=1.19-8.16 ; p=0.021)$ and $\mathrm{N}$-category $(\mathrm{RR}=4.77 ; 95 \% \quad \mathrm{CI}=1.81-13.54 ; \quad p=0.002)$ remained significantly associated with outcome. For tumor site $(\mathrm{RR}=1.06 ; 95 \% \mathrm{CI}=0.80-1.38 ; p=0.69)$, initial tumor stage $(\mathrm{RR}=1.29 ; 95 \% \mathrm{CI}=0.79-2.05 ; p=0.30)$, radiation dose $(\mathrm{RR}=2.15 ; 95 \% \quad \mathrm{CI}=0.67-6.76 ; \quad p=0.19)$ and surgery $(\mathrm{RR}=1.86 ; 95 \% \mathrm{CI}=0.69-4.95 ; p=0.21)$, no such association was observed on Cox regression analysis. 
Table II. Locoregional control (i.e. freedom from a second locoregional recurrence) following irradiation of recurrent head-and-neck cancer.

\begin{tabular}{|c|c|c|c|c|}
\hline & At 1 year $(\%)$ & At 2 years $(\%)$ & At 3 years $(\%)$ & $p$-Value \\
\hline \multicolumn{5}{|l|}{ Gender } \\
\hline Female $(n=17)$ & 70 & 70 & 70 & \\
\hline Male $(n=40)$ & 59 & 49 & 41 & 0.14 \\
\hline \multicolumn{5}{|l|}{ Tumor site } \\
\hline Oropharynx $(n=23)$ & 61 & 55 & 47 & \\
\hline Hypopharynx $(\mathrm{n}=1)$ & 0 & 0 & 0 & \\
\hline Larynx $(n=19)$ & 72 & 60 & 60 & \\
\hline Oral cavity $(n=14)$ & 51 & 51 & 34 & $\mathbf{0 . 0 2 0}$ \\
\hline \multicolumn{5}{|l|}{ Initial tumor stage } \\
\hline AJCC I-II (n=44) & 71 & 62 & 55 & \\
\hline AJCC III-IV $(n=13)$ & 30 & 30 & 30 & 0.017 \\
\hline \multicolumn{5}{|l|}{ Primary treatment } \\
\hline Surgery alone $(n=46)$ & 68 & 59 & 52 & \\
\hline $\mathrm{RT} / \mathrm{RCT}$ alone $(\mathrm{n}=2)$ & 50 & 50 & 50 & \\
\hline Surgery plus RT/RCT (n=9) & 32 & 32 & n.a. & 0.29 \\
\hline \multicolumn{5}{|c|}{ Time between cancer diagnosis and irradiation of locoregional recurrence } \\
\hline$\leq 24$ Months $(\mathrm{n}=29)$ & 58 & 53 & 46 & \\
\hline$>24$ Months $(\mathrm{n}=28)$ & 66 & 57 & 52 & 0.64 \\
\hline \multicolumn{5}{|c|}{ Age at RT of locoregional recurrence } \\
\hline$\leq 64$ Years $(n=31)$ & 62 & 52 & 46 & \\
\hline$\geq 65$ Years $(n=26)$ & 63 & 57 & 52 & 0.71 \\
\hline \multicolumn{5}{|l|}{ ECOG score at RT of recurrence } \\
\hline $0-1(n=32)$ & 77 & 69 & 61 & \\
\hline $2(n=25)$ & 36 & 29 & 29 & 0.004 \\
\hline \multicolumn{5}{|l|}{ T-category of recurrence } \\
\hline rT1-2 $(n=11)$ & 55 & 55 & 44 & \\
\hline rT3-4 $(n=30)$ & 65 & 51 & 51 & \\
\hline $\operatorname{rTx}(n=16)$ & 64 & 64 & 51 & 0.97 \\
\hline \multicolumn{5}{|l|}{$\mathrm{N}$-category of recurrence } \\
\hline rN0-1 $(n=32)$ & 71 & 71 & 61 & \\
\hline $\mathrm{rN} 2(\mathrm{n}=25)$ & 49 & 29 & 29 & 0.025 \\
\hline \multicolumn{5}{|l|}{ Surgery for recurrence } \\
\hline No $(n=22)$ & 31 & 24 & 24 & \\
\hline Yes $(n=35)$ & 78 & 71 & 63 & 0.004 \\
\hline \multicolumn{5}{|l|}{ Radiation dose for recurrence } \\
\hline$<60$ Gy $(\mathrm{n}=13)$ & 28 & 28 & 28 & \\
\hline$\geq 60$ Gy $(n=44)$ & 72 & 62 & 55 & 0.032 \\
\hline \multicolumn{5}{|c|}{ Concurrent chemotherapy for recurrence } \\
\hline No $(n=19)$ & 76 & 76 & 67 & \\
\hline Yes $(n=38)$ & 56 & 45 & 40 & 0.12 \\
\hline
\end{tabular}

AJCC: American Joint Committee on Cancer, RT: radiotherapy, RCT: radiochemotherapy, ECOG: Eastern Cooperative Oncology Group, n/a: not available, significant $p$-values are shown in bold.

\section{Discussion}

Despite improvement of outcomes after treatment of locally advanced squamous cell head-and-neck cancer (5-9), more than half of the patients experience locoregional recurrence during follow-up. Since often a complete resection cannot be achieved, RT or RCT are frequently used for these situations, either as a definitive treatment approach or as adjuvant treatment following (incomplete) resection $(1-3,10)$. Since patients' survival prognoses diverse considerably, it is recommended to tailor the treatment of the recurrent disease to their remaining lifetime. Patients with a short survival time should receive a less burdensome therapy with a short duration. For these patients, control and prevention of physically demanding symptoms have priority. In contrast, for patients with a substantially longer lifetime, long-term results in terms of disease control and survival are more important.

These reflections indicate that it would be quite important to be able to judge a specific patient's remaining life time. In order to achieve this goal, knowledge of predictive factors would assist the physicians who work out the patient's 
treatment plan. In addition to predictors of survival, such factors would also be important with respect to determining the likelihood of a second locoregional recurrence. Such factors could be helpful when deciding how aggressive treatment should be.

Therefore, the current study was performed in order to identify factors predictive of survival and freedom from a second locoregional recurrence. According to our results, a better performance score (ECOG 0-1) and a lower nodal category of the recurrence ( $\mathrm{rN} 0-1$ ) were independent predictors of better survival. With respect to freedom from a second locoregional recurrence, the same factors were independently associated with outcome. Taking into account the retrospective nature of these data, the following recommendations may be derived from these results. Patients with a less favorable performance score $(E C O G \geq 2)$ and a less favorable nodal category of the recurrence $(\mathrm{rN} \geq 2)$ likely experience poor prognoses and appear better suitable for a less burdensome and more palliative-oriented treatment. In contrast, patients with a good or very good performance score (ECOG 0-1) and a lower nodal category of the recurrence ( $\mathrm{rN} \mathrm{0-1)}$ are candidates for a cure-oriented, more aggressive regimen.

In conclusion, this study identified independent predictors of survival and freedom from a second locoregional recurrence in patients irradiated for locoregionally recurrent head-and-neck cancer. These predictors can assist the physician when aiming to prescribe the best possible individualized treatment for such a patient.

\section{Conflicts of Interest}

On behalf of all Authors, the corresponding Author states that there is no conflict of interest related to this study.

\section{References}

1 Lefebvre JL, Rolland F, Tesselaar M, Bardet E, Leemans CR, Geoffrois L, Hupperets P, Barzan L, de Raucourt D, Chevalier D, Licitra L, Lunghi F, Stupp R, Lacombe D, Bogaerts J, Horiot JC, Bernier J and Vermorken JB; EORTC Head and Neck Cancer Cooperative Group; EORTC Radiation Oncology Group: Phase 3 randomized trial on larynx preservation comparing sequential $v s$. alternating chemotherapy and radiotherapy. J Natl Cancer Inst 101: 142-152, 2009.
2 Bernier J, Domenge C, Ozsahin M, Matuszewska K, Lefèbvre JL, Greiner RH, Giralt J, Maingon P, Rolland F, Bolla M, Cognetti F, Bourhis J, Kirkpatrick A and van Glabbeke M; European Organization for Research and Treatment of Cancer Trial 22931: Postoperative irradiation with or without concomitant chemotherapy for locally advanced head and neck cancer. N Engl J Med 350: 1945-1952, 2004.

3 Cooper JS, Pajak TF, Forastiere AA, Jacobs J, Campbell BH, Saxman SB, Kish JA, Kim HE, Cmelak AJ, Rotman M, Machtay M, Ensley JF, Chao KS, Schultz CJ, Lee N and Fu KK; Radiation Therapy Oncology Group 9501/Intergroup: Postoperative concurrent radiotherapy and chemotherapy for high-risk squamouscell carcinoma of the head and neck. N Engl J Med 350: 19371944, 2004.

4 Kaplan E and Meier P: Nonparametric estimation from incomplete observation. J Am Stat Assoc 53: 457-481, 1958.

5 Chen LY, Huang CC, Tsou YA, Bau DT and Tsai MH: Prognostic factor of severe complications in patients with hypopharyngeal cancer with primary concurrent chemoradiotherapy. Anticancer Res 35: 1735-1741, 2015.

6 Rades D, Dziggel L, Hakim SG, Rudat V, Janssen S, Trang NT, Khoa MT and Bartscht T: Predicting survival after irradiation for brain metastases from head and neck cancer. In Vivo 29: 525-528, 2015.

7 Song JH, Jeong BK, Choi HS, Jeong H, Kang MH, Kang JH, Kim JP, Park JJ, Woo SH, Jang HS, Choi BO and Kang KM: Comparison of failure patterns between conventional and intensitymodulated radiotherapy for stage III and IV head and neck squamous cell carcinoma. Anticancer Res 35: 6833-6840, 2015.

8 Franco P, Potenza I, Schena M, Riva G, Pecorari G, Demo PG, Fasolis M, Moretto F, Garzaro M, Di Muzio J, Melano M, Airoldi M, Ragona R, Rampino M and Ricardi U: Induction chemotherapy and sequential concomitant chemo-radiation in locally advanced head and neck cancers: How induction-phase intensity and treatment breaks may impact on clinical outcomes. Anticancer Res 35: 6247-6254, 2015.

9 Fujimoto Y, Kato S, Itoh Y, Naganawa S and Nakashima T: A phase I study of concurrent chemoradiotherapy using oral s-1 for head and neck cancer. Anticancer Res 34: 209-213, 2014.

10 Denis F, Garaud P, Bardet E, Alfonsi M, Sire C, Germain T, Bergerot P, Rhein B, Tortochaux $\mathrm{J}$ and Calais G: Final results of the 94-01 French Head and Neck Oncology and Radiotherapy Group randomized trial comparing radiotherapy alone with concomitant radiochemotherapy in advanced-stage oropharynx carcinoma. J Clin Oncol 22: 69-76, 2004.

Received September 22, 2016

Revised October 13, 2016

Accepted October 14, 2016 